\title{
Rethinking The Going Concern Assumption As A Pre-Condition For Accounting Measurement
}

\author{
Saratiel Wedzerai Musvoto, North West University, Vaal Triangle Campus, South Africa
} Daan G Gouws, University of Pretoria, South Africa

\begin{abstract}
This study compares the principles of the going concern concept against the principles of representational measurement to determine if it is possible to establish foundations of accounting measurement with the going concern concept as a precondition. Representational measurement theory is a theory that establishes measurement in social scientific disciplines such as accounting. The going concern assumption is prescribed as one of the preconditions for measuring the attributes of the elements of the financial statements of an entity that is expected to continue in business for the foreseeable future. Studies in accounting measurement have so far not succeeded in establishing foundations of measurements under going concern. The findings of this study suggest that the going concern assumption is anti-measurement in nature. Consequently, the findings suggest that financial statements be prepared on a basis that distinguishes quantifications produced under conditions that facilitate accounting measurement from those that do not.
\end{abstract}

Keywords: going concern; modern principles of measurement; conjoint measurement; reality; simulated reality

\section{INTRODUCTION}

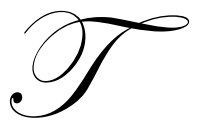

he establishment of the conditions under which a process of measurement is carried out is fundamental to an understanding of the measures it produces. Measurement literature (e.g., Luce $e t$ al., 1971; Narens, 2002; Stevens, 1951) asserts that measurements should be evaluated with respect to the conditions under which they have been prepared. This is necessary since measurements may be made under non-standard conditions, such that comparisons or the evaluation of such measurements could lead to misleading inferences.

In accounting, taking the going concern assumption is considered one of the preconditions for measurement to take place. According to the IASB (2009) framework for financial reporting, accounting measurements that are necessary for the preparation of the financial statements of companies whose operations are expected to continue into the foreseeable future should be prepared under the going concern assumption. In other words, the construction of accounting measurements should take into account the effects of the going concern assumption. The going concern assumption asserts that unless there is evidence to the contrary, it is assumed that the firm will continue indefinitely (Wolk et al, 2001:138). The going concern assumption is made when a company is ordinarily viewed as continuing in business for the foreseeable future with neither the intention nor the necessity of liquidation. It can be inferred from this that the going concern assumes a business that survives into the foreseeable future and that it assumes a successful business.

However, there is another school of thought that argues that it is not possible for measurement to occur under the going concern assumption. For example, Sterling (1968) points out that financial statements prepared under the going concern assumption are provisional and the truth of these statements is dependent on subsequent events. This suggests that the truth of accounting measurements made under the going concern assumption is also dependent on subsequent events. However, authors such as Luce et al (1971), Orbach (1978), Sterling (1979) and 
Walker and Jones (2003) believe that all measurements occur at a specific point in time. They argue that the purpose of measurement is to discover the magnitude at that point in time, regardless of what has gone before or what will happen afterwards. This means that the truth of measurements cannot be dependent on subsequent events. Indeed, it is clear that if financial statements prepared under going concern are dependent on subsequent events, it is doubtful whether accounting measurement actually takes place under the going concern assumption.

According to Stevens (1951) measurement in social sciences is established through the modern principles of measurement also known as the representational theory of measurement. Accounting is considered to be a social science (Flanders, 1961). This means that accounting measurement are bound by the principles of representational measurement. It follows therefore that if the going concern assumption is truly a precondition for accounting measurement to occur, then the principles of the representational theory of measurement should be in harmony with the accounting concept of measurement that is practiced under the going concern assumption.

Given the discussion above it is clear that these two schools of thought create confusion in the discipline as to whether or not measurement is possible under the going concern assumption. Furthermore, this creates confusion as to the empirical validity of accounting information produced under going concern. This study therefore suggests to discuss whether, accounting measurement is possible when the modern principles of measurement are applied within the context of the going concern assumption.

This study begins with a discussion of the representational measurement implications of the going concern assumption, in section 2. This is followed in section 3 by a discussion of the representational measurement implications of the concept of flowing business activities. The study goes on to explain the effects of the concept of futurity in accounting on the principles of representational measurement, in section 4 . The implications of the concept of time under the going concern concept on representational measurement are discussed in section 5. The effects of the entity concept on the application of the principles of measurement in accounting under the going concern postulate are covered in section 6 , and the foundations of representational measurement under the going concern postulate in section 7 . The conclusions and recommendations in section 8 close the study.

\section{THE GOING CONCERN POSTULATE AND REPRESENTATIONAL MEASUREMENT}

In section 1 above it was noted (Wolk et al., 2002:138) that the going concern postulate assumes that unless there is evidence to the contrary a firm will continue to exist indefinitely. It is clear from this that assets and liabilities are recorded in the financial statements on the assumption that the company will be able to realize its assets and discharge its liabilities in the normal course of business. The firm will also have to exist in the future so that it can receive its benefits from the realization of its assets and give up benefits in the settlements of its liabilities. Sterling (1997:498) puts it in the following way:

An asset is an asset because it will benefit the future and is valued on the present balance sheet on the basis of a past price. The firm will have to continue in the future in the manner expected at the present in order for the present allocations or past expenditures to be correct while the past allocations made on the basis of the past expectations of future events now need to be corrected to reflect present expectations of future events.

These words point out that an asset can only be considered to be such by a firm if the firm expects to continue for the foreseeable future. An asset can therefore only be classified as such under the going concern assumption. The extract also highlights the fact that financial statements prepared in the present under the going concern assumption do not contain empirical information. The information is provisional and has to be confirmed and verified at a future date. This perspective of going concern is in contrast to the principles of representational measurement. Narens (2002) asserts that all measurements must be a true reflection of the properties of the phenomena that they purport to represent. There must therefore be a one-to-one correspondence between measurements and the phenomena the measurements purport to represent. It is clear that the financial statements prepared under going concern cannot be empirically verified in the present and consequently they cannot be considered to be measurements. Willet (1988), notes that all measurable phenomena must be empirical. From this, however, it can be concluded that accounting phenomena are not measurable under going concern. 
Sterling (1979) believes that the determination of future economic benefits that are expected to be realized from assets and future economic benefits that are expected to be given up in settling liabilities is not a process of measurement. He argues that such a process is a forecasting process. This makes sense since the magnitude that is being quantified lies in the future. The use of the term "forecasting" indicates that the magnitude that is of interest in the present lies in the future. As a result, this magnitude cannot be empirically verified in the present. According to Decoene et al. (1995), magnitudes are historically and theoretically determined reflections of quantitative aspects of objectively existing entities and not merely the outcome of metricization or measuring procedures. It is evident from this line of reasoning that something that cannot be objectively determined cannot be measured. All future phenomena cannot be objectively determined, as they have not yet occurred. Thus, forecasts are not measurable. Therefore, values of assets and liabilities cannot be measured under the going concern postulates, as they are forecasts.

In addition, Sterling (1968:484) notes that income and position can only be estimated. He also argues that all statements prepared under going concern are provisional and dependent on subsequent events for the final and accurate statements to be prepared at liquidation. This means that under the going concern, the truth of accounting statements is dependent on future events. It is thus quite clear from this that the income statement and the statement of financial position are also dependent of future events. Luce et al. (1971:13) point out that the empirical relational structure should be seen as an objectively existing entity that is not bound by subjective assumptions of an individual. In other words, every empirical relational structure should be empirically testable. Therefore, if the information in the income statement and balance sheet under going concern is dependent on future events, this information cannot be considered to be objective. Hence it cannot be measurement information.

Paton and Littleton (1940) treated the going concern as an assumption and not as a factual statement. They argued that the going concern is of course a matter of assumption and this fact should not be lost sight of in the process of business reporting. An assumption is a belief or feeling that something is true or that something will happen although there is no proof (Hornby, 2005:77). No empirical evidence is required to make an assumption. Since the going concern is referred to as an assumption, then, this suggests that there is no proof of the existence of the going concern. Furthermore, it can also be inferred that there is no proof that the financial statements prepared under the going concern contain factual information. Thus, it is questionable whether financial statements contain measurement information.

As noted above (Sterling, 1968), in this section all statements prepared under going concern are provisional and inaccurate until the occurrence of some future events. Therefore, accounting measurements that occur under the going concern assumption cannot be considered an accurate reflection of the attributes of economic events. Luce $e t$ al (1971) makes the point that measurements should be a true representation of the properties of the objects that they purport to represent. Consequently, it follows that accounting quantifications that occur under going concern should not be considered as measurements.

Similarly, Gouws and Rehwinkel (2004:85) emphasize the view that it is not possible to produce accounting measurements under the going concern assumption when they state:

The going concern concept imposes the danger that the concept of time, and more specifically of the past and the future, can be incorrectly interrelated. Thereby the disclosure of reality over a given period or at a given point in time may be distorted. Since financial statements are prepared according to historical cost measurement procedures and simultaneously adhere to the futuristic going concern concept, a rather odd state of affairs is devised, namely that financial statement figures contain provisional, estimated or contingent futuristic allocations that are based on historical cost measurements.

This extract underlines the point that financial reporting that occurs under the going concern concept incorrectly interrelates the time of occurrence of events. It also contends that figures relating to past and future events are aggregated to each other. Consequently, such an aggregation creates a result that reflects neither the past nor the future. According to Sterling (1997), measurement is the discovery of an extant position that requires a present act. He argues that future magnitudes can be predicted and verified as they occur, but that measurements need to be made in the present. According to this, future events are not measurable. It is also clear that only 
phenomena that currently exist are measurable. Accounting figures that represent future events are structurally different from those that represent past or current events. It can therefore be concluded that financial statements prepared under the going concern assumption are not in harmony with the principles of the representational theory of measurement.

\section{REPRESENTATIONAL MEASUREMENT AND THE FLOWING ACCOUNTING EVENTS}

This section discusses the concept of flow in accounting. Hawker (2003:236) describes flow as "moving steadily and continuously in a current or stream". This means that the movement that is described as flow should be uniform and unbroken. According to Goldberg (2001:261), the concept of flow is primarily associated with liquids, but it can also be legitimately applied to gases and to granular substances such as sand or sugar. He also points out that the flow of occurrences which accountants take cognisance of is more analogous to that of a granular substance than that of a liquid or a gas. This viewpoint indicates that in a liquid, the constituent particles are homogeneous and they cannot be distinguished from each other structurally. Although gases and other granular substances can flow, their constituent particles are not homogeneous. They are distinguishable from each other structurally. It is evident that in this case the flow in accounting is constituted by separate events that are not homogeneous. That is, accounting events flow through a business during its lifetime, but they are heterogeneous. Goldberg (2001:261) puts it as follows: "Each occurrence can be likened to a grain of sand and can be readily dissociated from any other, if need be, and does not merge and completely lose its separate identity in the totality of activity". In other words, each accounting transaction is unique, separate and identifiable. It can also be reasoned from this that although different economic events keep their separate identities they have a homogeneous purpose. The purpose of economic events is to create profit for the business and it follows that the income from different economic events must be identical.

Kirk (2005) argues that under the going concern postulate a firm is assumed to continue indefinitely unless there is evidence to the contrary. It is also alleged that the true income of a firm cannot be calculated until the firm is dissolved (Sterling, 1968). Thus, one can infer that income can only be calculated once the flow of business activities has stopped. It follows from this that the going concern concept is necessary for flow of business activities. Moreover, the going concern concept is only possible if one assumes homogeneous business activities.

If individual business activities were viewed as independent and isolated, it would imply that the income produced from them should also be viewed as different. This view of business transactions makes income produced by all business transactions homogeneous. If, as outlined earlier (Sterling, 1968), the true income of an entity can only be measured at liquidation, it means that the creation of income is a continuous process, and at the point of liquidation, when it is possible to measure income, it would follow that all income has to be homogeneous. This perspective that suggests homogeneous income from business transactions is evidenced by the concept that all periodic income is aggregated to give the total income for the period.

If all business activities are seen as homogeneous, it would seem logical to assume that an identical method of measurement is used for measuring identical attributes of different business activities. But evidence from accounting literature indicates that there are numerous measurement methods that could be used at the same time on different business transactions. For example, Staubus (1985:53) states:

If a scientist in a field far removed from accounting asked an accountant to tell him the central ideas of accounting measurement practices, what could the accountant say? Could he say that historical cost is the basis of accounting measurement? Surely he could not feel that he has conveyed the essence of the subject by reference to a principle that applies to a minority of balance sheet items.

This suggests that there are numerous methods of measuring the attributes of accounting phenomena. If this was the case, it would defeat the point of seeing the income they produce as homogeneous. It would make sense if periodic income were classified according to the different classes of transactions or activities that produced it. It is senseless to use different measurement methods on identical phenomena. It makes sense, however, to suggest that different business transactions produce different income. It would make sense, then, to employ different measurement methods for different phenomena. 
Furthermore, Staubus (1985) contends that to his knowledge no one has woven accounting measurement practices into a comprehensive and coherent theory. This perspective highlights the fact that the underlying phenomena that are being measured are structurally different. That is to say, the phenomena themselves might be different and as a result they require different measurement methods and procedures. This leads to the development of different measurement theories for these phenomena. In addition, it should also be noted that there is no operation available in accounting that permits the aggregation of income produced by different accounting transactions. An operation that permits addition should indicate that the attributes that are used in the measurement of income are identical and that they are measured using an identical scale of measurement. Luce (1996) also points out that the homogeneity axiom requires that numerical representations of elements that are structurally different cannot be added to each other. This emphasizes that it is necessary to verify that measurements on an identical scale are representations of an identical phenomenon before they are added to each other. In this case, it seems that the numerical representations of the attributes of accounting phenomena are structurally different. If they were added, it could lead to disharmony with the homogeneity axiom of extensive measurement.

\section{MEASUREMENT AND THE PROBLEM OF FUTURITY IN ACCOUNTING}

The problem of futurity in accounting is directly linked to the going concern assumption. The going concern postulate provides a context for valuation. Wolk et al. (2001:138) stress that the reporting of liquidation values for assets and equities is in violation of the postulate. This suggests that the values of assets and liabilities of an entity should be reported in the financial statements on a basis that reflects that an entity will be able to realize its assets and discharge its liabilities in the normal course of business. The entity therefore has to exist in the future in order to realize benefits from its assets and to discharge its liabilities. It also follows that the measurement of future benefits cannot occur in the present, as these do not exist.

The phraseology of the going concern concept implies stability of the firm and the economy. Sterling (1968) argues that the implementation of present plans under the going concern postulate requires that future events be much the same as expected, i.e. costs; prices, technology, etc. must remain fairly stable. This point of view highlights the importance of using expectations to represent magnitudes of future phenomena. It also indicates that under the going concern assumption expectations should be accurate predictions of the magnitudes of future events. But Sterling (1979) asserts that predictions are not measurements: future events do not represent reality and as a result their attributes are not measurable. Orbach (1978) believes that expectations have legitimate properties in the present that are measurable. This suggests that the properties of expectations are real and are therefore measurable. But it should be noted that expectations of future events are not future events. Future events still remain immeasurable.

The going concern concept does not inherently mean continuing in an indefinite manner. No firm can continue forever. According to Sterling (1968), the length of continuity into the future is irrelevant to the going concern proposition. He argues that the significant point is that accountants are interested in the status of the firm at a given point in time in terms of its earning potential measured, to the extent possible, at the same point. It is this attempt to measure the earning potential of a firm at a given point in time that presents a measurement problem under going concern. Goldberg (2001) clearly points out that accounting transactions flow into the business entity until the point of liquidation. Before the point of liquidation, the accounting transactions flow non-stop through the business. As has been outlined above (Sterling, 1968), it is alleged that the true value of a firm is indeterminate prior to liquidation. Thus, legitimate properties of the income of the firm can only be obtained during liquidation.

Moreover, Sterling (1968) contends that present magnitudes under going concern are dependent upon subsequent events He also argues that present magnitudes can never be known because subsequent events always lie in the future. This suggests that the measurement of the real attributes of accounting phenomena is only possible at liquidation. It follows that one cannot measure a magnitude that lies in the future: it is only the expectation that can be measured. It is not possible to independently verify a magnitude that lies in the future. Furthermore, measurement magnitudes are historically and theoretically determined reflections of quantitative aspects of objectively existing entities and not merely the outcome of metricization or measuring procedures (Decoene et al., 1995). Indeed, one can see that representational measurement is only possible with empirical phenomena. It is clear then from this that the measurement of future phenomena is definitely excluded. 
Chambers (1997) notes, that, every particular measurement scheme requires the specification of the property of a class of objects that is of use and interest to the measure. A precise knowledge of the property that is being measured is thus necessary for measurement to occur. If a property lies in the future, a specific and precise definition of such a property in the present is impossible. One of the defining features of representational measurement is the belief that questions of measurement must be grounded in reality (Decoene et al., 1995). It is quite clear from this that all measurable phenomena must be empirical. That is to say, they should all be objectively existing entities at that moment in the present. It is thus clear that it is not possible to measure a future property in the present.

In addition, every particular measurement scheme requires the specification of a scale of some kind, making it possible to distinguish the extent to which every object in the class possesses the specified property (Chambers, 1997). This indicates that it is necessary to specify scales of measurement in a measurement process. It follows that it will be impossible to specify the scale of measurement for an unspecified property that cannot be empirically tested and that also lies in the future. A scale specifies the relationship between the empirical relational structure and the numerical relational structure. If a property lies in the future, its relationship with a numerical relational structure cannot be precisely specified. The reason for this is that a phenomenon lying in the future cannot be defined precisely as it does not exist. If such a relationship cannot be specified, measurement cannot take place. It is quite clear that the empirical relational structure of future events cannot be specified. It is only the expectations of future phenomena that have legitimate properties in the present that are measurable. In addition, it is not possible to specify the unit in the scale, and the conditions under which unit measurements shall be deemed to be of equal significance, as such measurements cannot be made.

\section{THE CONCEPT OF TIME IN ACCOUNTING}

The issue of time is of paramount importance in deciding whether or not the attributes of accounting phenomena are measurable. The classification of accounting phenomena is dependent on the concept of time. According to Gouws and van der Poll (2004), accounting phenomena are constituted by two types: namely: observed reality and simulated reality. They argue that time in accounting distinguishes between observed reality and simulated reality. The move from observed reality to simulated reality defines a change of time from the past to the present and to the future. Narens (2002), notes that the concept of representational measurement is applicable to phenomena that exist. It is clear then, that in accounting simulated reality is not measurable: it does not have attributes that are empirical. Only observed reality has attributes that are empirical and is therefore measurable.

The implications of the concept of time in accounting have been illustrated diagrammatically by Gouws' (2003) accounting arrow of time. Figure 4.1, which illustrates the arrow of time, was adapted from Gouws (2003). From this diagram it is clear that predicted or foreseen happenings become clearer as the future approaches. This is because our knowledge and information of the past comes from the fact that the procedures we use to arrive at beliefs about the past are generally more reliable than those generating predictions of the future (Gouws and Van der poll, 2004). As the future approaches different rules of employing the mathematical model of measurement in accounting measurement will be used. The arrow of time is illustrated in Figure $\mathbf{4 . 1}$ below:

The diagram indicates that in accounting, in the past and present, there are physical happenings, occurrences and transactions that represent reality. It is also clear from the diagram that reality can be empirically verified. The diagram also highlights that there is simulated reality in the future. The arrow of time also indicates that predictions, contingencies, allocations, provisions and reserves characterize accounting phenomena in the future, and that future phenomena are not based on reality. Consequently, future phenomena cannot be empirically verified, as they do not exist. Thus, accounting reality has attributes that are capable of being measured while simulated reality does not.

For measurement to occur it is necessary to have a full knowledge of the phenomenon that is being measured. Margenau (1959:165) points out that prior to measurement a precise theoretical construction of the attribute that is of use and interest to measure is necessary. That is to say, it is only the attributes of observed reality that are empirical and therefore they are measurable. With regard to simulated reality, the attributes of future events exist in the future and therefore, they cannot be measured in the present. Decoene et al. (1995) assert that 
magnitudes are historically and theoretically determined reflections of quantitative aspects of objectively existing entities and not merely the outcome of metricization or measuring procedures. This means that only existing phenomena are measurable. Orbach (1978:31) points out that expectations have legitimate properties at the present moment that are measurable. Future events have properties that lie in the future that cannot be empirically tested in the present and therefore are not measurable in the present. It is only the expectations of future events that can be measured in the present.

Figure 4.1 Accounting arrow of time (Gouws, 2003:11)

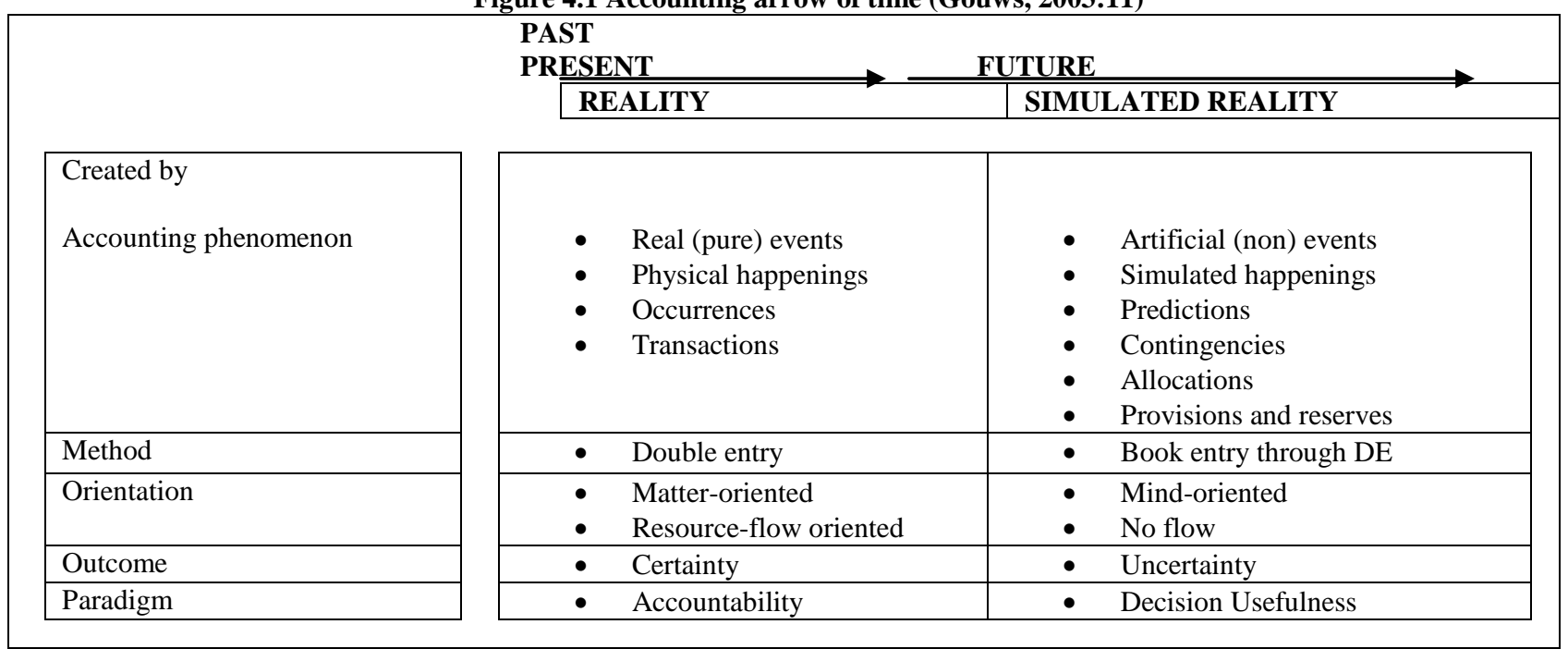

Source: Gouws (2003)

Decoene et al. (1995) emphasize that representational measurement requires the specification of an empirical relational system that can be represented by a numerical relational system. This requires an adequate understanding of the qualitative structure describing the attributes of the phenomenon to be measured. In order to form an adequate understanding of a qualitative structure, it is essential that the phenomenon being studied is empirical. But, if the phenomenon does not exist it cannot be fully understood. Caws (1959:8) notes in similar vein: "One has first a concept of some quality and looks afterward for quantitative expressions of it." It can be inferred from this that it is necessary to have precise knowledge of the object of measurement before measurement takes place. Once this precise knowledge has been established, one searches for a numerical relational structure that can be used to represent the attributes of the phenomenon. Therefore, if under going concern the attributes of accounting phenomena lie in the future, the empirical relational structure of these accounting phenomena cannot be specified and as a result the numerical relational system that corresponds to the empirical relational system cannot be known. For these reasons measurement cannot be said to have taken place. Therefore, representational measurement cannot take place currently under going concern.

\section{REPRESENTATIONAL MEASUREMENT AND THE ACCOUNTING ENTITY}

According to Luce et al., (1971) every pair of the representation and uniqueness theorems involves a choice of a numerical relational structure. They also argued that the choice of this structure is a matter of convention and that the conventions are strongly affected by considerations of computational convenience. It is evident from this that the choice of a numerical relational structure is arbitrary, and varies with the viewpoint of the parties doing the measuring. It also follows that the proofs of the representation and uniqueness theorems for the measurement of value in accounting are dependent on an arbitrary choice of the numerical relational structure. It can also be inferred that the choice of a numerical relational structure that can be used to represent an empirical relational structure varies across different social settings. Moreover, Narens (2002) makes the point that the construction of a scale of measurement depends on the choice of a numerical relational structure. Therefore, if the 
choice of a numerical relational structure is arbitrary, this implies that the construction of a scale of measurement is also arbitrary.

In the discipline of accounting the choice of the numerical relational structure is also dependent on the accounting entity. According to Staubus (1985), the accounting entity is an economic unit under one management. $\mathrm{He}$ also argues that the scope of the management determines the boundaries of the entity. It can be inferred from this that the nature of the economic activities occurring in a business entity are dependent on the social context of that business entity. Tinker (1985) points out that the purpose of accounting is to resolve social conflicts. It follows that the nature of accounting measurement is dependent on the type of social conflicts to be resolved. The choice of a numerical relational structure for a pair of the representation and uniqueness theorems in the measurement of the value of economic phenomena is thus also dependent on the type of social conflicts to be resolved. It is also evident from this that the construction of a scale of measurement is dependent on the wishes of management. One can go as far as to say that different economic entities may have different scales of measuring value. If the scales of measuring value are different for different entities, then value measurements made across these different entities cannot be compared unless they are converted to a common scale of measurement.

As has been noted in section 2 (Wolk et al., 2001), the financial statements of entities whose operations are expected to continue indefinitely should be prepared under the going concern assumption. This indicates that the measurement of the values of the elements of the financial statements for a company whose operations are expected to continue indefinitely is also done under the going concern assumption. Sterling (1968) argues that the financial statements prepared under the going concern assumption are provisional and their truth is dependent on the occurrence of subsequent events. Sterling's argument suggests that the nature of accounting phenomena in the present, under the going concern postulate, depends on the occurrence of future events. That is, the empirical properties of accounting phenomena can only be known with certainty under the going concern postulate on the occurrence of subsequent events. If this is the case, the contents of financial statements prepared under the going concern postulate do not represent economic reality but rather a simulation of economic reality. It is only a speculation of what might happen in the future. Speculations are subjective and highly dependent on the view of the speculator. Consequently, the integrity of the information will suffer.

Luce et al. (1971) point out that it is only empirical phenomena that are measurable. This suggests that speculations about the future are not measurable as they are not empirical. Earlier in this section (Staubus, 1985), it was noted that the scope of the management's influence determines the boundaries of the entity. This suggests that the wishes of management determine the nature of the speculations that are made under going concern. This makes expectations about future events highly dependent on the views of management. Consequently, measurement under the going concern postulate is highly dependent on the views of management.

The specification of a homomorphism in a process of measurement is specific to an entity. Luce et al. (1971: 13) highlight the fact that the numerical scales of measurement are subject to arbitrary conventions. They also argue that these conventions are strongly affected by considerations of computational convenience. Thus, it can be inferred from this that the measurement choices of an accounting entity are relative to a specific entity. Mattessich (1964:79) also classifies accounting measurements as measurements by fiat. This implies that accounting measurements are relative to a specific environment and consequently they should be evaluated relative to that environment. According to Stevens (1951), measurement is an especial preoccupation of psychophysics, not only in the narrow sense of the term, but in its older and broader spirit, which attempts to reveal rules relating the responses of organisms to the energetic configurations of the environment. This indicates that the general economic environment and the specific environment of a specific business entity affect accounting measurement, and that accounting measurements are unique to a specific entity.

Given the vast differences between firms (Sterling, 1968), it is difficult to conceive of identical conditions of measurement for them. This view is consistent with the view that representational measurement equates measurement with numerical coding. Decoene et al. (1995) assert that numerical coding always involves a conventional component, that is, the agreement to code certain empirical attributes with certain numbers, and certain empirical relations with certain numerical ones. The use of the term "coding" indicates that a particular group of people could agree to measure a phenomenon in a way that is unique and understandable to them. This suggests that 
individuals who are not part of that group might not be familiar with the coding system used by the group. Therefore, unless there is an agreement across different accounting entities, accounting measurements can never be common across them and consequently, they cannot be among different users.

\section{THE FOUNDATIONS OF REPRESENTATIONAL MEASUREMENT UNDER THE GOING CONCERN ASSUMPTION}

The discussion in this section focuses on the importance of foundations of measurement in a process of measurement on whether accounting measurement under going concern is based on foundations that can be empirically tested. According to Luce et al. (1971), every process of measurement must be based on specified foundations of measurement that can be empirically tested. Authoritative accounting literature (e.g., IASB, 2009; Wolk et al., 2001), points out that accounting is a measurement discipline and that accounting measurement occurs under going concern. If accounting measurement occurs under going concern, then there must be empirically testable foundations of measurement under going concern. Luce et al. (1971:13) argue that in analyzing the foundations of measurement one of the main concerns is formalization. They point out that in analyzing foundations there is a need to formalize the choice of an empirical relational structure as an abstraction from the available data, the choice of an appropriate numerical relational structure, the discovery of suitable axioms and the construction of numerical homomorphisms. These recommendations are discussed as follows:

- The choice of an empirical relational structure as an abstraction from the available data-The specification of an empirical relational structure is essential because it provides the empirical identity of the properties that are subject to measurement. Its formalization ensures that the individuals in that particular community of measurement are aware of the object of measurement. Such formalization guarantees that measurements are meaningfully compared. Measurement symbolism must be agreed upon before measurements from different frames of measurement are compared.

- $\quad$ The choice of an appropriate numerical relational structure- The need to formalize a numerical relational structure ensures that the nature of the representation is familiar to the users of the measurement information. Luce et al. (1971: 13) point out that every pair of representation and uniqueness theorems involves a conventional choice of a numerical relational structure. They argue that these choices are entirely arbitrary and depend on the considerations of computational convenience. The use of the term "arbitrary" indicates that the numerical relational structure can be chosen without the use of any set rules or plans. This indicates that unless there is an agreement in measurement symbolism between different measurement frames, measurements cannot be compared.

- The discovery of suitable axioms- Axioms are true statements about the attributes of an empirical relational structure. They specify the true statements of the characteristic that is being measured. If axioms were not specified measurement would not be possible. The formalization of axioms ensures that the individuals in the same community of measurement have identical views about the characteristics of the empirical relational structure that are being measured. It facilitates the comparability of measurements in a community of measurement.

- $\quad$ The construction of numerical homomorphisms- A homomorphism is a scale of measurement (Luce $e t$ al., 1971). A scale specifies the relationship between the empirical relational structure and the numerical relational structure. The formalization of the construction of homomorphism ensures that an identical scale of measurement is used by a particular group of people in the same community of discussion.

In the accounting literature, there are suggestions that the properties of accounting phenomena are not empirically testable and that it is thus not possible to establish an empirical relational structure from accounting data. Heath (1987) asserts that notions such as income and owner's equity are concepts without any reality behind them. Since measurement is only possible with empirical phenomena, this suggests that they are not measurable under any circumstances. Sterling (1968:4) also claims that,"with rare exceptions accounting numerals do not represent phenomena, any phenomena". The use of the phrase "rare exceptions" suggests that many accounting phenomena are not measurable. Willet (1987) points out that the attribute that is currently being measured in accounting is not known. This indicates a representation problem in accounting. That is to say, it is not known what accounting quantifications represent. He argues that the only thing that is measured in accounting is the numerosity of monetary units, and it is not known exactly what this numerosity represents. It is evident from this 
that the rare exception of measurement in accounting is the numerosity of monetary units.

Goldberg (2001) argues that economic transactions flow into a business entity during its lifetime. The concept of "flow" introduces the idea of motion into the accounting discipline. This reflects the entrenched belief in the accounting discipline that accounting events are in motion. Ijiri (1989) attempted to base the foundations of accounting measurement on the physical laws of motion. This attempt to base the foundations of accounting measurement on the structure and terminology of laws of motion in physics is open to criticism. The initial criticism comes from the viewpoint that accounting is a social science and its foundations of measurement are currently not analogous to that of a natural science. Ijiri (1989) regards accounting wealth as corresponding to the physical quantity of mass times distance. This is not compatible with the representational measurement principles of additive conjoint measurement. For instance, according to Luce et al. (1971:245), the concept of momentum is a composite entity that is composed of several elements. They point out that their mass and velocity affect the attribute "momentum" of a physical object. Thus momentum is not a phenomenon that has a separate existence from its mass and its velocity. Rather, momentum exists as a result of the mass and velocity of the object. That is, there is no apparent empirical relational structure of momentum. The empirical relational structures that are apparent in momentum are those of mass and velocity. Luce et al. (1971) believe that for momentum to be measurable, the two components that constitute it must be independently realizable. This means that these components (mass and velocity) must be capable of being measured independently of each other. In the determination of momentum, these two components can be measured independently (see, Luce et al., 1971:246). Therefore, if wealth is a composite entity that is analogous to the physical quantity of mass times distance, then its components should be specified and they should be capable of being measured independently of each other, just like mass and velocity in the determination of momentum. But since it is not known currently what wealth is in accounting (McLean, 2006; Tinker, 1985), it is currently not possible to assert that wealth is measurable.

Ijiri (1989:85) also takes income momentum (called "momentum" = growth rate of wealth per time unit) to correspond to linear momentum (mass times velocity=mass distance per time). Currently, however, the quantity income momentum cannot be known because one of its components, "wealth", is not known. Furthermore, there are no specifications of the attributes of wealth that correspond to mass and the attributes that correspond to distance when the analogy of wealth to mass times distance is made. The mass of an object remains constant while distance changes with motion. Therefore, what is constant in wealth and income is not specified in any way. From the discussion above, it seems that the mathematical principles of natural philosophy are not relevant to accounting measurement. It is also important to note that the concept of momentum is only applicable to a phenomenon that exists: only a phenomenon that exists can possess mass and velocity. Income is a non-existent phenomenon and cannot therefore possess momentum. For example, Stamp (1981) points out that, income is an ambiguous concept that is not an intrinsic property of an accounting entity. There is no agreement among researchers in the field of accounting on the meaning or relevance of income. The IASB (2009, Para 70) framework for financial reporting defines income as follows: "Income is increases in economic benefits during the accounting period in the form of inflows or enhancements of assets or decreases of liabilities that result in increases in equity, other than those relating to contributions from equity participants." If income is an enhancement of assets and the benefits from assets are enjoyed in the future, it means that the benefits of income also exist in the future and do not exist in the present. It follows that it is not possible to have an income momentum in the present. In addition, the concept of income cannot be precisely defined (Tinker, 1985; Stamp, 1981), but the particles in physics have a precise definition. This means that no meaningful analogy can be made between accounting phenomena and physical phenomena.

Gouws and Rehwinkel (2004:82) also assert that no meaningful analogy can be made between natural and man-made phenomena when they state:

The accounting product is a human artifact and not a natural phenomenon, which has more bearing on the classical sciences. Its product is art (hence the definition), a perception of reality.

This extract points out that accounting values cannot be inferred through natural laws: accounting values are not natural phenomena. It is clear that the properties of accounting values cannot be compared to the properties of natural phenomena. Accounting values cannot be measured using the same principles that are used to measure 
natural phenomena. Waldrop (1992:39) supports this view:

Classical science focuses on explanation and on laying bare the fundamental mechanics of nature. That is what biologists, geologists and astronomers do in their fields.

This points to the fact that natural phenomena can be inferred through natural laws, and that natural phenomena have characteristics that are different from artificial phenomena. It is thus clear that no sensible analogy can be made between natural and artificial phenomena. Consequently, there can be no analogy between accounting and classical sciences.

The discussion in this section presents the apparent lack of accounting measurement foundations. It seems that the accounting discipline is not clear on exactly what is measured in accounting. It is therefore not possible to classify accounting as a measurement discipline until such time that there is clarity on what is measurable and what is not in accounting.

\section{SUMMARY AND CONCLUSIONS}

Literature in the discipline of accounting currently outlines that the going concern assumption is necessary for the preparation of the financial statements of an entity that is expected to continue in operation for the foreseeable future. Accounting literature also indicates that it is possible to measure the attributes of accounting phenomena under the going concern assumption. However, it has been argued in this chapter that this is in fact not possible. A summary of some of the main points is given below:

- $\quad$ Under the going concern principle, business activities are assumed to flow non-stop through a business entity until the point of liquidation.

- Income is considered to be an ambiguous concept that is not an intrinsic property of an accounting entity. As a result, there is no agreement among accountants about the meaning or relevance of income.

- The going concern concept assumes profitability. It has been argued that nobody would expect a firm that is continuously making losses to continue into the foreseeable future. The going concern assumption is only possible if one assumes that the status quo of business activities will be maintained in the future. The phraseology of the going concern concept implies stability of the firm and the economy. However, the fact that accounting phenomena have always happened in a certain way does not logically lead to the conclusion that this will be the case tomorrow. The problem with the going concern principle is that of generalizing from a limited number of observations. There are many unknown variables in the future and as a result it is difficult to conceive that the business will continue in the future in the manner that is expected of it in the present.

- Assuming a going concern automatically implies the existence of a liquidating entity. Therefore, the intuitive beliefs that stem from the economic environment suggest the existence of a business world consisting of specific entities.

- $\quad$ The concept of measurement is only applicable to empirical phenomena.

The discussion in this study has highlighted the fact that many accounting variables are not directly observable as they lie in the future. Some authors have attempted to base the foundations of accounting measurement on the foundations of physics, but without success. This is because, accounting is a social science and currently its foundations cannot be analogous to those of a natural science. As a result, it is necessary to develop foundations for accounting measurement that are based on its status as a social science.

\section{RECOMMENDATIONS}

Although the going concern concept is anti- measurement in substance, the quality of accounting measurement information can be enhanced by considering the following recommendations that have come to light in the course of this study: 
- It is necessary to distinguish accounting quantifications according to whether they qualify as measurements under the going concern. In this regard it is only expectations that qualify as measurements under going concern, but with current implications. Furthermore, other numerical assignments should be carefully examined to determine whether they qualify as measurements under the modern principles of measurement and conditions under which they qualify should also be specified in the financial statements.

\section{AUTHOR INFORMATION}

S Wedzerai Musvoto, $\mathrm{PhD}$ is a senior lecturer in Financial Management and Accounting at the School of Accounting Sciences of the North-West University's Vaal Triangle Campus. He received his PhD from the University of Pretoria in 2008. Dr Musvoto is also affiliated with the Association of Chartered Certified Accountants and the Chartered Institute of Management Accountants. His research interests include accounting measurement, risk management and the implications of modern principles of measurement on finance theory development.

Prof Daan Gouws is a Professor in the Faculty of Economic and Management Sciences of the University of Pretoria in South Africa. Dr Gouws is the author of many refereed papers regarding trans disciplinary research in accounting, finance and educational issues. He is co-editor of various refereed journals and is(was) the supervisor of more than 120 master's and doctoral students. Prof Gouws won in 2000 the national award as the "Most outstanding Accounting and Finance Educator" in South Africa.

\section{BIBLIOGRAPHY}

1. Caws, P. (1959). Definition and Measurement in physics, in C. West Churchman and Philburn Ratoosh, eds. Measurement, Definitions, and theories, John Wiley \& Sons, Inc.

2. Chambers R.J, (1997), Wanted: Foundations of Accounting Measurement. Abacus, 34 (1): 36-47.

3. Decoene, S., Onghena, P. and Janssen, R. (1995). Representationalism under Attack. Journal of Mathematical Psychology, 39: 234-242.

4. Flanders, D., P. (1961) Accountancy, Systematized Learning, and Economics. The Accounting Review, 36: 564-576.

5. Goldberg, L. (2001). A journey into the accounting thought. Edited by: Leech, S.L Routledge, London

6. Gouws, D.G. (2003). Accounting's Time Paradigm. Unpublished research paper. University of Pretoria.

7. Gouws, D.G. and Rehwinkel. A (2004), Financial accounting and reporting: Sustaining relevance in the present time paradigm. Meditari Accountancy research, 12 (1): 101-117.

8. Gouws, D.G. and Van der Poll H.M. (2004), The integrity of information created through book entries. Meditari Accountancy research, 12 (1): 101-117.

9. Hawker, S. (2003), The Little Oxford Dictionary, Thesaurus, and Word Power Guide, Oxford University Press.

10. Heath L.C. (1987). Accounting Communication and the Pygmalion Syndrome, Accounting Horizons, March: 1-8.

11. Hornby. A.S. (2005), Oxford Advanced Learner's Dictionary of Current English, Oxford University Press, Oxford

12. Ijiri. Y. (1989) Momentum Accounting and Triple - entry Bookkeeping: Exploring the Dynamic Structure of Accounting Measurements, Sarasota FL: American Accounting Association.

13. International Accounting Standards Board (IASB), 2009, International Financial Reporting Standards (IFRS) (2009): Including International Accounting Standards (IAS) and interpretations as at 1 July 2009. Vol 1A, 1B, \& IC London: IASB

14. Kirk, R.J. (2005). International Financial Reporting Standards In Depth, Volume 1: Theory and practice, CIMA Publishing, An Imprint of Elsevier, Linacre House, Jordan Hill, Oxford OX2 8DP, 30 Corporate Drive, Burlington, MA 01803.

15. Luce, R, D., (1996), The ongoing Dialog between Empirical Science and Measurement Theory, Journal of Mathematical Psychology, 40: 78-98.

16. Luce, R. D., Krantz, D.H., Suppes, P. and Tversk, A. (1971), Foundations of Measurement, (Vol. 1) Additive and Polynomial representations, New York: Academic Press 
17. Margenau, H. (1959), Philosophical Problems Concerning the meaning of Measurement in physics," in C. West Churchman and Philburn Ratoosh, eds. Measurement, Definition and theories, John Wiley \& Sons, Inc: 136-165.

18. Mattessich R. (1964). Accounting and Analytical Methods, Homewood 3, Irwin.

19. McLean, R. (2006), New Concepts in Measuring Value, in (Ed), Einstein in the Boardroom, John Wiley \& Sons, Inc.

20. Narens, L. (2002). A meaningful justification for the representational Theory of Measurement, Journal of Mathematical Psychology, 46: 746-768.

21. Orbach, K.N. (1978). Accounting as a Mathematical Measurement Theoretic Discipline, Unpublished PhD Thesis, Texas A\& M University.

22. Paton, W. A. and Littleton, A.C. (1940), An introduction to Corporate Accounting Standards, American Accounting Association

23. Stamp, E. (1981), Why can Accounting not become a Science like Physics? Abacus, June: 13-27.

24. Staubus, G. J. (1985). An induced Theory of Accounting Measurement, The Accounting Review, January, 60(1): 53-75.

25. Staubus, G. J. (2004). Two views of Accounting Measurement. Abacus, 40 (3): 265-279.

26. Sterling, R.R. (1968). The Going Concern: An Examination, The Accounting Review, July: $481-502$.

27. Sterling, R.R. (1979). Towards a science of Accounting, Accounting publications of Scholars book co.

28. Sterling, R. R. (1997). The quest for a science of accounting: An anthology of the Research of Robert $R$ Sterling, Edited by T.A. Lee and P.W. Wolnizer, Garland Publishing Inc, New York.

29. Stevens, S.S. (1951). Mathematics, Measurement and psychophysics, in (Ed), Handbook of Experimental psychology, New York: Wiley.

30. Suppes, P. (1951). A set of Independent Axioms for Extensive Quantities, Portugal, Math, 10: $163-172$.

31. Tinker, T. (1985). Paper Prophets, A Social Critique of Accounting. New York: Praeger.

32. Waldrop, M.M. (1992). Complexity: The Emerging Science at the Edge of Order and Chaos, Simon \& Schuster, New York.

33. Walker, R.G.and Jones, S. (2003). Measurement: A way forward, Abacus: 39 (3): 356-374.

34. Willet, R.J. (1987), An Axiomatic Theory of Accounting measurement, Accounting and Business Research: $155-171$.

35. Willet, R.J. (1988), An Axiomatic Theory of Accounting Measurement - Part 2, Accounting and Business Research, 19(73): 79-91.

36. Wolk, H.I., Tearney, M.G. and Dodd, J.L. (2001), Accounting Theory: A conceptual and Institutional Approach, South Western College Publishing. 
NOTES 